\title{
Negociando el imperio: el Estado inca como culto
}

Édifier l'Empire par la négociation: le culte de l'État inca

Negociating Empire: the Inca state as a cult

\section{Susan Elizabeth Ramírez}

\section{OpenEdition \\ Journals}

Edición electrónica

URL: http://journals.openedition.org/bifea/3201

DOI: $10.4000 /$ bifea.3201

ISSN: 2076-5827

Editor

Institut Français d'Études Andines

Edición impresa

Fecha de publicación: 1 abril 2008

Paginación: 5-18

ISSN: 0303-7495

Referencia electrónica

Susan Elizabeth Ramírez, « Negociando el imperio: el Estado inca como culto », Bulletin de l'Institut français d'études andines [En línea], 37 (1) | 2008, Publicado el 01 octubre 2008, consultado el 26 noviembre 2020. URL : http://journals.openedition.org/bifea/3201 ; DOI : https://doi.org/10.4000/ bifea.3201

\section{(c) $(1) \odot$}

Les contenus du Bulletin de l'Institut français d'études andines sont mis à disposition selon les termes de la licence Creative Commons Attribution - Pas d'Utilisation Commerciale - Pas de Modification 4.0 International. 
Primera Parte

EL TIEMPO DE LOS ANTIGUOS 



\title{
Negociando el imperio: el Estado inca como culto*
}

\author{
Susan Elizabeth Ramírez**
}

\begin{abstract}
Resumen
Este trabajo establece una conexión entre el sistema de creencias inca y la construcción de un Estado multiétnico con el objetivo de reevaluar las principales motivaciones detrás de la expansión inca. En este ensayo se documenta el hecho que el así llamado «imperio inca» era menos un imperio en el sentido romano del término que una congregación de creyentes en un culto estatal, caracterizado por un personaje central, manifestación del divino fundador, quien se desplazaba por distintos centros de peregrinación en donde él o sus representantes negociaban los términos de la participación en dicho culto. Esta imagen no corresponde a la de una organización altamente centralizada y omnipotente, sino más bien a la de una entidad en la cual la flexibilidad y el compromiso terminaban imponiéndose, y en la cual los grupos étnicos suscribían, en distinta medida, un conjunto de mandatos centrales. El vínculo entre creencias religiosas o cosmológicas, por un lado, y la transformación de un curacazgo basado en el parentesco en un Estado inacabado, unificado por relaciones sanguíneas o rituales de parentesco y vinculado sobrenaturalmente al culto a los ancestros, por otro, se explica como un medio para acceder a la mano de obra necesaria para la conservación de la etnia gobernante.
\end{abstract}

Palabras clave: imperio, Inca, culto, cosmología, mano de obra, centros sagrados y de peregrinaje

\section{Édifier l'Empire par la négociation : le culte de l'État inca}

\section{Résumé}

Cet essai met en relation le système de croyances des Inca avec la construction d'un État multiethnique dans le but de réévaluer les facteurs principaux qui ont motivé leur expansion. L'idée est proposée selon laquelle le soit-disant Empire inca, à la différence du modèle romain, consistait davantage en un regroupement de sujets fidèles au culte d'État. Celui-ci était ????? par un personnage central, manifestation du fondateur divin, qui se rendait en différents lieux de pélerinage, où il négociait, en

* Este texto ha sido traducido por José Carlos de la Puente Luna.

** Texas Christian University, Fort Worth, Texas. E-mail: s.ramirez@tcu.edu 
personne ou par représentants interposés, les termes de la participation à ce culte. On n'est donc pas en présence d'une organisation omnipotente et hautement centralisée, mais plutôt d'une construction où règnent la flexibilité et le compromis, et à laquelle les groupes ethniques adhèrent, à divers degrés, aux injonctions du pouvoir central. Le lien entre les croyances religieuses ou cosmologiques et la transformation d'un caciquat - fondé sur la parenté en un État inachevé, qu'unifient des attaches familiales réelles ou fictives ainsi que le culte à un ancêtre d'origine surnaturelle — , sert à assurer l'accès à la force de travail nécessaire à la conservation de l'ethnie au pouvoir.

Mots clés : empire, Incas, culte, cosmologie, main d'oeuvre, lieux de pélerinage

\title{
Negociating Empire: the Inca state as a cult
}

\begin{abstract}
This paper makes a connection between the Inca belief system and the construction of a multi-ethnic state structure to reassess the motivating factors for Inca expansion. It documents the fact that the so-called Inca empire was less an empire in the Roman sense than a congregation of believers in a state cult, characterized by a central personage, the manifestation of a divine founder, who traveled to different pilgrimage centers, where he or his representatives negotiated the terms of cult participation. This is not a picture of a highly-centralized, omnipotent organization, but one where flexibility and compromise triumph and where ethnic groups adhere to central dictates to various degrees. The tie between religious belief or cosmology and the on-going transformation of a kin-based curacazgo into an unfinished state, unified by real or fictional kinship ties and a supernaturally-linked ancestor cult, is explained as a means of gaining access to the additional labor resources necessary for the ultimate preservation of the ruling ethnicity.
\end{abstract}

Key words: empire, Inca, cult, cosmology, labor, pilgrimage centres

\section{LAS MOTIVACIONES TRAS LA CONQUISTA}

En contraste con la generación de estudiosos de la religión inca que los precedió, los investigadores que han tratado el tema a lo largo de los últimos cuarenta años y que pusieron un énfasis mayor en los aspectos político-económicos han ofrecido a sus lectores la descripción de un imperio militarista y centralizado cuyo Rey gozaba de poderes omnipotentes (Jijón y Caamaño, 1919). Numerosos historiadores, antropólogos y arqueólogos, entre otros, han enfatizado los aspectos militares y económicos tras la expansión, tomando como punto de partida el desafío lanzado por los chancas (Patterson, 1991; Espinoza Soriano, 1978; Murra, 1980; Rowe, 1946). Las motivaciones aducidas para explicar el imperialismo inca van desde la adquisición de tierras y el sistema de herencia partida1, sugeridas por Geoffrey Conrad y Arthur Demarest, pasando por el intercambio de bienes, hasta llegar a la necesidad de garantizar el acceso a bienes exóticos como la concha Spondylus, indispensable en el ritual religioso, hipótesis esta última sugerida por María Rostworowski (Rostworowski, 1977, cap. 2; Conrad, 1981; Conrad \& Demarest, 1984).

1 Se trata de una forma de sucesión según la cual un heredero principal recibe el puesto de mando, además de los derechos inherentes y las tareas del funcionario difunto. Las posesiones personales y las fuentes de riqueza de éste son asignadas, en cambio, a los otros descendientes en tanto miembros de un grupo corporativo de descendencia (Conrad \& Demarest, 1984: 91). 
Esta visión estereotipada de un estado centralizado, militarista y ávido de recursos refleja en parte la tradición oral recogida en el Cuzco, la cual emanaba de la élite nativa sobreviviente en el siglo XVI. Con el fin de engrandecerse, los miembros de la élite seleccionaron y transmitieron determinadas historias y memorias. Sin embargo, le dieron una nueva estructura a la información con el objetivo de adaptarla a los paradigmas culturales occidentales, agregando de paso un poco de bravata y de exageración a las historias resultantes. Estudios recientes demuestran que los primeros cronistas recogieron un puñado de historias particulares entre muchas otras, precisamente aquellos relatos más acordes con sus propias expectativas y experiencias en la ciudad del Cuzco y el área circundante que con la realidad nativa, tal como la sugieren otras regiones de los Andes (Ramírez, 2006b). Una visión más equilibrada del imperio inca, es decir, una interpretación que tome en consideración las evidencias históricas y arqueológicas de los grupos étnicos sometidos, se aleja definitivamente de la imagen occidental de un imperio centralizado y burocrático, aproximándose más bien a la concepción de un poder central cuyo control sobre otros grupos era limitado y precario, incluso secundario, pero de una importancia absolutamente crucial para los argumentos de este ensayo.

Este trabajo establece una conexión entre el sistema de creencias inca y la construcción de un Estado multiétnico con el objetivo de reevaluar las principales motivaciones detrás de la expansión inca. En este ensayo se documenta el hecho que el así llamado «imperio inca» era menos un imperio en el sentido romano del término que una congregación de creyentes en un culto estatal, caracterizado por un personaje central, manifestación del divino fundador, quien se desplazaba por distintos centros de peregrinación en donde él o sus representantes negociaban los términos de la participación a dicho culto. Esta imagen no corresponde a la de una organización altamente centralizada y omnipotente, sino más bien a la de una entidad en la cual la flexibilidad y el compromiso terminaban imponiéndose, y en la cual los grupos étnicos suscribían, en distinta medida, un conjunto de mandatos centrales. El vínculo entre creencias religiosas o cosmológicas, por un lado, y la transformación de un curacazgo basado en el parentesco en un Estado inacabado, unificado por relaciones sanguíneas o rituales de parentesco y vinculado sobrenaturalmente al culto a los ancestros, por otro, se explica como un medio para acceder a la mano de obra necesaria para la conservación de la etnia gobernante2.

\section{COSMOLOGÍA ANDINA}

Los pobladores andinos vivían vidas precarias. Sequías, inundaciones, sismos, erupciones volcánicas y heladas, plagas y enfermedades eran algunas de las amenazas al sostenimiento de la vida misma. Los habitantes de los Andes desarrollaron sistemas de creencias para explicar estos sucesos y guiar así las acciones de la sociedad. En pocas palabras, los pobladores andinos rindieron culto a sus antepasados porque les atribuían el poder de influir sobre el clima y la naturaleza, así como de intervenir activamente en la vida diaria de la comunidad. Entre los linajes, el fundador del grupo se convertía en el ancestro apical, objeto de culto por sus descendientes. Los pobladores andinos creían que, incluso luego de haber pasado al otro mundo, sus fundadores y ancestros les garantizarían fertilidad y protección ante enfermedades y desastres, siempre y cuando se les mantuviera satisfechos a través del culto y de los constantes sacrificios. Si se les hacía caer en el olvido o se les hacía

2 Un grupo de personas cuya identidad se basaba en la existencia de un ancestro común. Uso el término como sinónimo de comunidad. Para unas perspectivas sobre lo religioso en la vida de los incas, véase Pease (1991b) y Regalado (1993: 42, 82, 105). 
enfurecer, estos mismos ancestros podían enviar desastres y calamidades, enfermedades e incluso la muerte. En términos ideales, la sucesión se transmitía desde el fundador del linaje y a través de los distintos grados de edad, descendiendo luego a las generaciones inferiores. En vida, los líderes, llamados Ilactayoc o marcayoc (términos traducidos en el español del siglo XVI como «dueño de indios» [Ramírez, 2006a]), tomaban el nombre y el supuesto estatus del ancestro apical, siendo obedecidos en tanto encarnaciones y portavoces de dichos ancestros (Ramírez, 2006b). Las fuentes de los siglos XVI y XVII sugieren que el espíritu del ancestro podía poseer a las autoridades nativas con la finalidad de comunicarse directamente con sus descendientes y seguidores (Duviols, 1978: 134; 1986: 143; Garcilaso, 1966: 52; Cieza, 1984: 268; MacCormack, 1993: 113-14; Millones, 1998: 35; Castro-Klarén, 1993: 169).

Los sacrificios y las ofrendas de los vivos hacia los muertos a cambio de bienestar tenían su contraparte en las expectativas mutuas entre los líderes y sus súbditos. De solicitárseles, éstos conformaban grupos de trabajadores para varios proyectos y por distintos periodos. A cambio, esperaban recibir las herramientas y los alimentos mientras duraban sus tareas, así como ser remunerados por su buen rendimiento. Por su parte, los líderes, muchos de ellos considerados descendientes directos de algún héroe fundador, organizaban y dirigían los rituales asociados al culto de los ancestros, garantizando así la ayuda sobrenatural necesaria para el mantenimiento de la vida. De ahí se desprende la necesidad de los líderes de mostrarse generosos - reciprocar con chicha y comida a los súbditos que les ofrecían su fuerza de trabajo-, así como la responsabilidad de interceder con el mundo de lo sobrenatural en tiempos de crisis.

Si la crisis se originaba en un desafío proveniente de otro linaje, el conflicto se solucionaba a través de una prueba de fuego. Los andinos iban a la batalla como fieles de su dios fundador. Creían que el poder de un dios frente al de otros determinaba la victoria o la derrota. Al vencedor pertenecen los despojos, así como el honor y el prestigio del triunfo. Las divinidades derrotadas, Ilamadas atisqa, descendían a una posición subordinada, inferior a la de la divinidad victoriosa, siendo en adelante obligadas a servir al dios más poderoso y a su gente3.

\section{LA EXPANSIÓN INCA}

En la mayoría de relatos históricos, el origen del imperio inca se remonta a la amenaza chanca, la cual condujo, después del triunfo, a la expansión y la transformación del curacazgo inca en una fuerza multiétnica, unificada precaria e imperfectamente por la promesa de conseguir el favor del dios Sol. A riesgo de simplificar demasiado, se puede concluir que la construcción del imperio coincidió con la construcción y la difusión del culto solar entre las poblaciones andinas de origen no Inca.

Cuando el líder chanca Uscovilca, quien era «más poderoso de gente» (Betanzos, 1996 [1551]: 19; Betanzos, 1999 [1551]: 23; Espinoza Soriano, 1980: 183), retó al Inca Viracocha, este y sus hijos, incluyendo al mayor y predilecto — Inca Urco- decidieron huir. El hijo menor, Ilamado Inca Yupanque (luego Pachacuti), decidió quedarse para defender el status quo, solicitando la ayuda de los linajes de las inmediaciones. Pocos o ninguno respondieron al llamado. Inca Yupanque, turbado y afligido, tuvo entonces una visión según la cual una imagen, que el Inca identificó como la del Sol, le prometió auxilio 
para conseguir la victoria. En el campo de batalla, las piedras se transformaron en guerreros que ayudaron a Inca Yupanqui a conseguir el triunfo, demostrando así que el Sol era más poderoso que Uscovilca, el ídolo chanca ${ }^{4}$. En su condición de atisqa, los chancas y su dios fueron entonces sometidos al dominio inca. Los incas capturaron al ídolo enemigo y exigieron a los chancas que adoraran al Sol, que aprendieran el quechua imperial y que prestaran sus servicios cuando les fuera requerido. Este episodio constituye el origen del culto imperial al Sol, así como la génesis de la expansión del curacazgo inca5. Al momento de la invasión española en 1532, los incas ejercían su dominio sobre más de ochenta grupos étnicos en los Andes, desde lo que es hoy el sur de Colombia hasta el Chile central, y desde el Océano Pacífico hasta Bolivia y el noroeste de Argentina (Betanzos, 1996 [1551], caps. $6-9$ y 17$) 6$.

\section{EL IDEAL DEL ÚNICO ORIGEN Y LA LEY SUPREMA DE LOS INCAS}

En el culto estatal, el Inca — cuyo título era «El Cuzco»— actuaba como el centro del centro. Las personas lo veneraba en su calidad de manifestación viviente de los míticos ancestros celestiales y antecedentes: el Sol y la Luna (Ramírez, 2005, caps. 2-3: especialmente pp. 68-69). La persona del Cuzco vivía en un contexto altamente ritualizado, rodeado por asistentes religiosos, mujeres escogidas y sirvientes con responsabilidades diversas. Los cortesanos restringían estrictamente el acceso al soberano. Fuera de su círculo privilegiado, el Inca se mostraba y era reconocido como un dios parlante que, sin embargo, hablaba en contadas ocasiones y normalmente a través de un portavoz. Transportado en una litera, el Inca se trasladaba de un lugar a otro para trabar relaciones con señores étnicos de menor jerarquía o reforzar las relaciones ya existentes. En términos ideales, el Inca actuaba también como un dios que administraba justicia sentado en los ushnus 7 , ubicados en los centros ceremoniales andinos dispersos en los Andes y que Felipe Guaman Poma de Ayala llamara «otra[s ciudades de los] Cuzco[s]». Se esperaba de él que intercediera ante los dioses con el fin de garantizar la fertilidad general y obtener la protección divina de los fieles contra las enfermedades. En tiempos de sequía, inundación, cataclismo o hambruna, el Inca podía proveer ayuda gracias a los depósitos imperiales. En centros de peregrinación como Huánuco Pampa, Incahuasi y Tumipampa, la generosidad institucionalizada era la regla (Guaman Poma de Ayala, 1980 [1613]: 185 [187]).

Esta visión del mundo estimuló la transformación de un pequeño curacazgo de los Andes del sur en una organización panandina de gran amplitud. El objetivo central era incorporar a todos los grupos étnicos que tendieran una amenaza a la supervivencia de la élite inca dentro de un megalinaje o nación, un conjunto de personas vinculadas por un único origen y viviendo bajo la ley suprema del Inca (Salomon \& Urioste, 1991: 71). Dado que las poblaciones andinas no establecían distinciones entre lo religioso y lo secular, su incorporación al imperio, así como la reorganización inherente a este proceso, eran sinónimo de la difusión y el desarrollo del culto solar.

4 Betanzos identifica a Uscovilca como un jefe étnico; Sarmiento $(1907: 87,92)$ hace la precisión de que se trataba de un hombre que se transformó en un ídolo y un dios; y Albornoz (1967: 28) equipara el nombre con una huaca (Ramírez, 2005: 98). Acerca de las piedras como guerreros, véase Garcilaso (1966: 280).

5 Ziólkowski (1991: 63-64) sostiene que el Sol se volvió el culto principal como resultado de la amenaza chanca.

6 Acerca del número de grupos étnicos, véase Rowe (1946: 186-92). Acerca del conflicto entre los incas y los chancas, véase Sarmiento (1907: 87, 91-92) y Sarmiento (1988: 88).

7 Una plataforma religioso-administrativa central presente en centros ceremoniales. 
Los linajes subordinados insertaron al Sol en el ápice de su jerarquía divina. Como una forma de facilitar dicha inserción, el Inca enviaba misioneros que enseñaran los rituales del culto solar y difundieran el uso del quechua imperial. También levantaron templos al Sol y acllahuasis (recintos para las mujeres escogidas) en asentamientos como Tumipampa, Tumbes y Pachacámac (Ramírez, 2005: especialmente p. 55). Estas monumentales construcciones se convirtieron en centros de peregrinación cuyo número sobrepasaba con creces el de las pocas fortalezas identificadas en las crónicas, hecho que reitera la importancia de la conversión religiosa para la empresa imperial inca.

Además de la reeducación in situ y de la conversión de la población, la persona del Cuzco exigía que los hijos de los líderes étnicos viajaran a la corte para aprender las formas del imperio. Guaman Poma de Ayala menciona que instituciones formalmente dedicadas a la educación operaban con este propósito (Guaman Poma de Ayala, 1936 [1613]: 329; Valcárcel, 1961: especialmente el cap. 7). Tras completar su educación, y a veces luego de largos años de servicio personal en la corte, algunos de estos jóvenes regresaban a sus comunidades de origen para gobernar como representantes privilegiados del Inca. Ésa es, precisamente, la historia de Chuptongo, hijo del curaca de Cajamarca llamado Concacax, mientras se establecía el dominio inca en la zona. A la muerte de Concacax, su hijo, quien era tan solo un niño, fue llevado a la corte por Túpac Inca Yupanqui. Allí, Chuptongo aprendió las artes del mando, convirtiéndose con el tiempo en el tutor del joven hijo del Inca, Huayna Capac, y ejerciendo incluso la regencia durante la minoría de edad de éste. Llegado el momento, Chuptongo recibió la autorización de Huayna Capac para regresar a Cajamarca y establecerse como gobernante de Guzmango (Villanueva Urteaga, 1986, II: 337).

La instrucción religiosa, apuntara ésta al individuo o al grupo, vinculaba a las poblaciones subordinadas con un código moral, una ley suprema que constituía uno de los objetivos principales de la estrategia imperial de unificar a un considerable número de linajes disímiles. En un contexto sin fuerza policíaca permanente, y en el cual el servicio militar se limitaba de ordinario a las temporadas no destinadas a la agricultura, los incas comprendieron que disponer de un conjunto de valores comunes era imperativo para organizar una civilización en expansión. Esto pone en evidencia que el soberano inca, así como los artífices de la expansión imperial, sabían que, en el largo plazo, la persuasión moral era un medio más eficiente para mantener alianzas y asegurar lealtades que el uso directo de la fuerza (Himmerich y Valencia, 1998: 8).

En parte, esta conversión religiosa implicaba la incorporación de las divinidades ancestrales de un determinado linaje al panteón imperial dominado por el Sol. Como se mencionara líneas arriba, los incas tomaban posesión de los ídolos de los dioses vencidos, ubicándolos en el nivel inferior de la jerarquía religiosa imperial. A pesar de que los oficiantes de estas divinidades locales seguían ocupándose de su culto en la corte, y sus seguidores seguían venerándolos como antes, estos dioses eran despojados de su lugar preeminente por el Sol. Las divinidades «cautivas» eran ponderadas y agasajadas según su importancia, siendo recompensadas o sancionadas anualmente de acuerdo con las predicciones y las acciones de sus seguidores. Sin duda, los incas llegaron a comprender que los devotos de un determinado ídolo se mostrarían menos inclinados a cuestionar o a resistir la dominación inca si es que la fuente y el sostenimiento del poder del linaje se mantenía (irónicamente) bajo la «custodia» y «protección» del Estado. En pocas palabras, la difusión de la instrucción religiosa y la reorganización de las jerarquías divinas terminaron por imponer la ley suprema de los incas sobre la costumbre local (Albornoz, 1967: 25).

Paralelamente a la conversión y la adopción de las divinidades específicas a cada linaje, los incas promovieron la reestructuración de las jefaturas étnicas. Ya fuera en la ciudad del Cuzco o en su desplazamiento por los centros regionales de peregrinación, los incas 
itinerantes negociaban con los distintos líderes étnicos tanto su estatus como los términos del servicio a ellos debido. Los incas confirmaban a las autoridades adeptas como un medio de establecer y consolidar su dominio indirecto. Aquellos señores que aceptaban la generosidad institucionalizada y las ofertas de alianza, recibían del Inca un conjunto de insignias asociadas con la autoridad, tales como literas, finos tejidos y dúhos o tianas. Estos presentes reforzaban la legitimidad de los líderes del linaje, a la vez que cimentaban sus vínculos con el estado en expansión. Para los señores étnicos, la posesión de una litera conllevaba el privilegio de ser transportados en hombros por sus súbditos. El señor de Chincha, por ejemplo, despertó varios comentarios por ser transportado en una litera durante la procesión de la persona del Cuzco en Cajamarca en 1532. El dúho o tiana simbolizaba el ushnu inca, desde el cual el soberano ordenaba el mundo y administraba justicia (Ramírez, 2005: 185, citando a Pizarro, 1978 [1571]: 37; Martínez Cereceda, 1995).

El Inca podía honrar también a un jefe étnico entregándole una o más mujeres. En algunos casos, el Cuzco ofrecía a los señores más importantes alguna hermana o mujer escogida (aclla) para que éstos las tomaran por esposas principales. El jefe del linaje podía reciprocar entregando a una hija o una hermana, a quienes el Inca aceptaba como algunas de sus esposas secundarias. Un buen ejemplo proviene de Huaylas, caso estudiado por Rafael Varón Gabai, Waldemar Espinoza Soriano y otros. En Huaylas, Huayna Capac contrajo «matrimonio» (casado a su modo) con dos de sus esposas secundarias, quienes eran hijas de los señores de las dos parcialidades principales (Ananguaylas y Ruringuaylas [también Luringuaylas]) (Varon Gabai, 1993: 729-731; Espinoza Soriano, 1976: especialmente pp. 249, 254). Gracias a esta alianza, la siguiente generación, es decir los hijos de dichas uniones, permaneció muy cerca de la persona del Cuzco. Si la esposa de un señor étnico era hermana del soberano inca, entonces los hijos de aquél eran parientes directos (sobrinos) del monarca. Mediante el intercambio de esposas, las autoridades de distintos grupos étnicos y sus descendientes fueron incorporados a una gran red de parentesco cuyos miembros podían rastrear su origen común hasta el Sol. La formación de un pueblo unificado por un mismo origen fue otro de los componentes principales de la estrategia imperial inca.

En otras circunstancias, la alianza y posterior incorporación al imperio eran negociadas. Por sus méritos extraordinarios, algunos personajes eran declarados «incas de privilegio». En otros casos, los líderes de linajes negociaban su estatus y aprobación. Así, por ejemplo, un líder étnico de Recuay llamado Caque Poma entregó la vida de su hija como capacocha8 a cambio de la confirmación de su posición y de los símbolos externos de su autoridad (Pease, 1990: 195-96; 1991: 68; Rostworowski, 1988: 147; D'Altroy, 2002: 89; Ramírez, 2005: 123; Hernández Príncipe, 1923 [1621-1622]: 52, 57; Szeminski, 2001: 163)9.

Las sanciones del Cuzco en caso de resistencia contrastaban con la magnanimidad y relativa benevolencia antes descritas. Las fuentes primarias mencionan casos de caciques «alzados», así como otras revueltas. La abierta rebelión era suprimida sin piedad. Fernández de Oviedo alude al caso de un señor de la costa llamado Pabor (también, Pabur), el cual es testimonio de la violencia imperial:

«E súpose que este cacique era grand señor e tenía mucha población algun tiempo antes, e que estaba destruido al presente, porque dijo que el señor del Cuzco, padre de Atabaliba, le había quemado e asolado veinte pueblos, e le había muerto

8 Se refiere a un sacrificio ofrecido al Rey, usualmente de una persona joven o un niño.

9 Sobre las negociaciones entre el estado inca y las linajes locales, véase Kaulicke (2004: especialmente 336-337); Sillar \& Dean (2002: especialmente 209-210, 232, 246-247); y Bárcena (2002: especialmente 278). 
la gente de ellos porque no le había experado de paces» (Fernández de Oviedo, 1992 [1535-1545, 1559]).

En otras ocasiones, los incas remplazaban a líderes sospechosos con individuos de su propia elección. Esta posibilidad quizás explique por qué los colliques de Lambayeque eran gobernados, en la década de 1560, por un señor con un nombre quechua (Sancho, 1938: 170; Quipucamayos, 1920 [1541-1544]: 20-21, 52; Betanzos, 1996 [1551]: 107, 121, 128, 140, 215; Caballo Balboa, 1951 [1586]: 290, 298, 314, 331, 335, 338; Fernández de Oviedo, 1992 [1535-1545, 1559], V: 39; Archivo General de las Indias (Sevilla)/[Secciones] Justicia 458; Justicia 459, 3127v; Justicia 461, 862; Justicia 462, 1769v; y Escribanía 528C, 809.

Para disminuir posibles focos de resistencia entre los grupos recalcitrantes, así como para utilizar más eficientemente la mano de obra de aquellos pueblos bajo su dominio, los incas extraían a algunos miembros de estas poblaciones para que vivieran entre familias pertenecientes a otros linajes. Esta estrategia cumplía dos propósitos. En primer lugar, neutralizaba la oposición de una población al separar a algunos de sus miembros del grupo principal. El reubicar a aquellos de origen no inca entre quienes ya habían sido aculturados y se mostraban leales al Estado acortaba el tiempo necesario para que aprendieran el quechua, además de darles la oportunidad de participar en el ya establecido culto solar. En segundo lugar, este tipo de reubicación era un medio para beneficiarse mejor de las habilidades de agricultores y de artesanos como los plateros y los ceramistas (Morales, 1977; Wachtel, 1977; Cieza, 1967: 195; D’Altroy, 2002: 303; Rostworowski, 1989: 275; Espinoza Soriano, 1969-1970).

Mientras la jurisdicción político religiosa inca se incrementaba a través de la proliferación de líderes de linajes adeptos, las estructuras de la autoridad étnica fueron reconfiguradas sobre la base del sistema decimal. Evidencias documentales tempranas de Jayanca, Riobamba, Jauja y el Altiplano demuestran que, con anterioridad a la incorporación inca, los líderes de linajes que asumían el poder adquirían los nombres de los ancestros. Con el paso del tiempo, dichos nombres se volvieron sinónimo del estatus adscrito a una determinada posición (Ramírez, 2006b). La identificación de los grandes señores y de los líderes de menor rango se volvió dificultosa al multiplicarse el número de grupos étnicos bajo la hegemonía inca. Una forma de solucionar la posible confusión fue reemplazar los nombres particulares con una nomenclatura que indicaba precisamente el poder y la jerarquía de cada autoridad. Así, además de sus nombres, los líderes de linajes asumieron un título acorde con la dimensión del grupo al que lideraban. En teoría, los funcionarios incas identificaban a los jefes étnicos y a las poblaciones que gobernaban a partir de su tamaño, comenzando, en el extremo superior, con el número 10000 familias. La jurisdicción de estos señores, llamados Hunos, se dividía en unidades de mil familias (guaranga) y éstas en pachacas de cien. Las subdivisiones de este sistema decimal se prolongaban hasta llegar a la autoridad («mandoncillo») a cargo de tan solo cinco familias. Estos títulos, más que nombres personales e individuales, servían para señalar a las autoridades imperiales el estatus y rango de cada uno de los líderes subordinados (Santillán, 1927: 16; Polo de Ondegardo, 1917 [1571], 51; Parssinen, 1992: 380-81).

\section{LA «MEJOR DEFENSA ES EL ATAQUE»}

Desde el punto de vista de los dominados, la adhesión al culto del Sol representaba la búsqueda de seguridad en un mundo de mucha inseguridad. La victoria de los incas sobre sus rivales chancas y sobre otras etnias dejó sentada su reputación y demostró que tanto 
él como su pueblo gozaban del favor de una divinidad poderosa, reconocida por todos como omnipresente y crucial para la diaria supervivencia. A través de su representante, el Sol prometía ayuda efectiva en tiempos de dificultad. Los distintos linajes respondían a las solicitudes de ayuda con la finalidad de garantizar el apoyo del estado en caso de necesidad.

En un mundo que definía la riqueza en términos del número de adeptos, la lealtad de las masas, desde el punto de vista imperial, era un elemento crucial para gobernar y para mantener el dominio. La tierra per se no constituía un estímulo en una era sin propiedad privada y con recursos relativamente abundantes (excepto quizás en los alrededores del centro ritual llamado el Cuzco, por los españoles, y del lago Titicaca). De forma similar, el control directo sobre los bienes de intercambio suntuarios y su distribución tampoco constituía un aliciente debido a que el intercambio en sí y no el control de los recursos era la forma típica de proveerse de bienes exóticos, tal como lo menciona Betanzos para el caso de determinadas variedades de coca (Betanzos, 1996 [1551]: 171-172). El acceso a una enorme cantidad de mano de obra constituía la fuente del poder de la persona del Cuzco, así como el sustento de su capacidad para ordenar la construcción de determinados trabajos públicos. Las masas construían y mantenían la enorme red de caminos y mesones (tambos), erigían y cultivaban los andenes, cavaban y limpiaban los canales de irrigación y transportaban bienes a los depósitos estatales. Súbditos leales y dispuestos proveían a los incas de la fuerza de trabajo necesaria para complacer los pedidos de asistencia y para satisfacer o inclusive superar las expectativas de sus súbditos. La capacidad de brindar protección y ayuda a los necesitados también suponía el movilizar a uno o más linajes con el fin de combatir a aquellos rivales que amenazaran la hegemonía inca. Así, a pesar de que, en el corto plazo, la amenaza chanca provocó una reacción defensiva, la expansión preventiva fue el principal legado en el largo plazo. Las acciones ofensivas exitosas - ya emplearan éstas los mecanismos pacíficos de la invitación y la persuasión o recurrieran en cambio a la fuerza y la amenaza bélica - conllevaban el control de mano de obra adicional por parte del estado inca, fuerza de trabajo ésta destinada a satisfacer la necesidad de sustentar o de socorrer a las poblaciones aliadas. En pocas palabras, las claves para asegurar la lealtad de la gente eran la reciprocidad, la liberalidad y la creencia en que el Inca representaba al dios más poderoso del panteón. El culto solar era la argamasa, la base sobre la cual fue posible construir una identidad más allá del linaje particular y cimentar la lealtad hacia la persona del Cuzco y sus descendientes. Los incas sabían muy bien que desatender los clamores y pedidos de ayuda o, peor aun, sufrir una derrota, incidirían negativamente en su prestigio y en el de su dios supremo. Las etnias conquistadas que aceptaban la supremacía del culto solar esperaban que el Inca actuara como un dios y que aliviara sus penurias. Sin embargo, el rendir culto al Sol no significaba que éstas dejaran de venerar a sus propios ancestros fundadores. En realidad, estos individuos, aparentemente politeístas, practicaban el henoteísmo, según el cual se adoraba a un dios a la vez con el fin de conseguir diversas formas de ayuda para distintos propósitos. La lógica detrás de estas creencias consistía en que, de fallar una divinidad, se podía recurrir a la ayuda de otra.

Las numerosas divinidades, así como las autoridades que las representaban, competían entre sí por la mano de obra y las ofrendas de una población de potenciales y tal vez precarios adherentes. De fracasar en satisfacer las expectativas de sus súbditos, el Inca perdería su estatus de antepasado protector e intermediario del Sol. Sus súbditos dudarían o inclusive se negarían a responder a sus solicitudes de mano de obra y de servicio personal. Alternativamente, de sufrir una derrota, el Inca se vería reducido a la condición de atisqa. En ambos casos, la persona del Cuzco y su culto enfrentarían una crisis de legitimidad y caerían en un estatus de subordinación. Los líderes serían eliminados o reemplazados por su debilidad, mientras que los ídolos antes venerados serían tenidos en cautiverio por 
los vencedores. La gente abandonaría el culto en busca de la protección de otro dios. La congregación de devotos del Sol se fragmentaría, los trabajos públicos se detendrían, la expansión se paralizaría y el centro perdería su magnificencia. En un escenario de decadencia tal, el puesto privilegiado del Sol y de sus representantes colapsaría al buscar las personas otros protectores e intermediarios. Así, la supervivencia inca en tanto élite dependía de la expansión, al menos hasta que todas las amenazas posibles hubieran sido contrarrestadas. Es cierto que la conquista e incorporación de las poblaciones fue imperfecta. Algunos grupos étnicos mantenían relaciones más cercanas y duraderas con el centro que otros. Pero es innegable que una masa demográfica crucial proveyó a los incas con el capital social requerido para responder a las expectativas y poder vivir así como dioses, convirtiéndose estas masas en el motivo subyacente para la expansión y la auto-conservación10.

En la práctica, sin embargo, la extensión del dominio y del poder de los reyes inca nunca fue completa. La historia de resistencia y rebelión, especialmente en tiempos de transición, así como la invasión de los europeos en 1532, demostraron que la aceptación del culto solar fue más bien superficial y más lenta que el avance de la conquista y la incorporación (Ramírez, 2005, cap. 3). Además, las distancias eran difíciles de cubrir, a pesar de los excelentes caminos y de la funcionalidad para la comunicación del sistema de chasquis. Más allá de las peregrinaciones eventuales, de la participación en el ritual religioso y de la entrega siempre negociada de mano de obra, la vida de la mayoría de los campesinos se veía solo ligeramente afectada por la pertenencia al culto estatal (Hayashida, 2003: 312)11. De forma similar, la presencia del tocricoc (gobernador inca) y de los jueces especialmente comisionados era más bien esporádica (Nowack, 2004; Santillán, 1927: 17; Albornoz, 1967: 21). En consecuencia, el sólido control centralizado era más aparente que real, especialmente en las fronteras sociales del imperio.

\section{EL CULTO IMPERIAL COMO MODELO}

La profunda lógica religiosa reconstruida aquí recupera un ritmo cíclico para la historia andina. Este mismo esquema de auge y decadencia, expansión y repliegue, puede explicar el debilitamiento y la posterior desaparición del estado Tiawanaku en tiempos de constante sequía. En tal contexto, la élite, sin desmedro de los sacrificios rituales y las plegarias a los dioses, habría fracasado en atraer las Iluvias. El modelo supone que las personas habrían abandonado el culto y su identificación con la élite, volviendo a recurrir a sus ancestros más inmediatos en busca de alivio. Sin el capital social necesario para mantener la esperada reciprocidad, la élite Tiawanaku habría perdido importancia y, eventualmente, habría desaparecido en tanto poder de alcance imperial (Ramírez, 2005: cap. 4). Esto explica también por qué Atahualpa se quejaba de que sus sirvientes ya no querían atenderlo luego de su derrota a manos de los españoles, así como por qué una resistencia más organizada y efectiva fracasó inmediatamente después de la captura del Inca en noviembre de 1532. El trabajo de Sabine McCormack, publicado en 1991, demuestra que, entre las poblaciones locales, los cultos étnicos ancestrales sobrevivieron mucho tiempo más que el culto solar Inca. No sería hasta el surgimiento del Taqui Onqoy (1565) que, una vez más, una esperanzada población andina predijo que, abandonando todas las maneras españolas,

10 Véase, por ejemplo, la reacción de las tropas del Inca cuando Huayna Capac disminuyó sus raciones (Cabello Balboa, 1951 [1586]: 375-78).

11 Los incas limitaban el servicio personal en las minas a un 1 \% de la población de un determinado grupo étnico. En tal sentido, la carga parece no haber sido muy onerosa. Véase, además, Ramírez (1996, cap. 4) y Cieza (1967: 195). 
sus dioses recobrarían las fuerzas y emergerían una vez más para liderarlos en una batalla triunfal contra los invasores ibéricos.

\section{Referencias citadas}

ALBORNOZ, C. de, 1967 - Instrucción para descubrir todas las guacas del Piru y sus camayoc y haciendas. Journal de la Société des Americanistes, 56 (1): 7-39.

BARCENA, R., 2002 - Perspectivas de los estudios sobre la dominación Inka en el extremo austral-oriental del Kollasuyu. Boletín de Arqueología, VI: 277-300; Lima.

BETANZOS, J. de, 1996 [1551] - Narrative of the Incas, 326 p.; Austin: University of Texas Press.

BETANZOS, J. de, 1999 [1551] - Suma y narración de los Incas, 299 p.; Cusco: Universidad Nacional de San Antonio Abad del Cusco.

CABELLO VALBOA, M., 1951 [1586] - Miscelánea antártica, 561 p.; Lima: Universidad Nacional Mayor de San Marcos.

CASTRO-KLAREN, S., 1993 - Dancing and the Sacred in the Andes: From the Taqui Onqoy to Resu-ñiti. In: New World Encounters (Stephen Greenblatt, ed.): 159-176; Berkeley: University of California Press.

CIEZA DE LEÓN, P. de, 1967 - El señorío de los Incas, 271 p.; Lima: Instituto de Estudios Peruanos.

CIEZA DE LEÓN, P. de, 1984 - Crónica del Perú: Primera Parte, 352 p.; Lima: Pontificia Universidad Católica del Perú.

CONRAD, G. W., 1981 - Cultural Materialism, Split Inheritance, and the Expansion of Ancient Peruvian Empires. American Antiquity, 46 (1): 3-24.

CONRAD, G. W. \& DEMAREST, A. A., 1984 - Religion and Empire: The Dynamics of Aztec and Inca Expansionism, 266 p.; New York: Cambridge University Press.

D'ALTROY, T. N., 2002 - The Incas, 391 p.; Malden, Mass.: Blackwell Publishers.

DUVIOLS, P., 1978 - Camaquen, Upani: Un concept animiste des anciens péruviens. In: Amerikanistische Studien/Estudios Americanistas: Festschrift für Hermann Trimborn (Roswith Hartmann \& Udo Oberem, eds.): 132-144; St. Augustin, Germany: Haus Völker und Kulturen, Anthropos-Institut.

DUVIOLS, P., 1986 - Cultura Andina y represión, 570 p.; Cusco: Centro de Estudios Rurales Andinos «Bartolomé de las Casas».

ESPINOZA SORIANO, W., 1969-1970 - Los mitmas yungas de Collique en Cajamarca, Siglos XV, XVI y XVII. Revista del Museo Nacional, 36: 9-57; Lima.

ESPINOZA SORIANO, W., 1976 - Las mugeres secundarias de Huayna Capac: Dos casos de señorialismo feudal en el imperio Inca. Revista del Museo Nacional, 42: $247-$ 298; Lima.

ESPINOZA SORIANO, W., 1978 - Los modos de producción en el imperio de los Incas, 390 p.; Lima: Editorial Mantaro.

ESPINOZA SORIANO, W., 1980 - Acerca de la historia militar inca. Allpanchis, XVI: 171 86.

ESPINOZA SORIANO, W., 1986 - La poliginia señorial en el reino de Cuismanco. In: Historia de Cajamarca (Fernando Silva Santisteban, Waldemar Espinoza Soriano, Rogger Ravines, eds.): 69-108; Cajamarca: Instituto Nacional de Cultura. 
FERNÁNDEZ DE OVIEDO, G., 1992 [1535-1545/1559] - Historia general y natural de las Indias. In: Biblioteca de Autores Españoles, 5 vols.; Madrid: Atlas Editores.

GARCILASO DE LA VEGA, I., 1966 - Royal Commentaries of the Incas, 1530 p.; Austin: University of Texas Press. Harold V. Livermore, traductor.

GUAMAN POMA DE AYALA, P., 1936 [1613] - Nueva coronica y buen gobierno, 1178 p.; París: Institut d'Ethnologie.

GUAMAN POMA DE AYALA, P., 1980 [1613] - Nueva coronica y buen gobierno (John V. Murra \& Rolena Adorno, eds.), 3 vols., 1175 p.; México: Siglo Veintiuno.

HAYASHIDA, F., 2003 - Leyendo el registro arqueológico del dominio inka: reflexiones desde la costa norte del Perú. Boletín de arqueología, VII: 305-20; Lima.

HERNÁNDEZ PRÍNCIPE, LICENCIADO R., 1923 - Mitología Andina (1621-1622). Inca: Revista trimestral de estudios antropológicos, 1: 25-78; Lima.

HIMMERICH Y VALENCIA, R., 1998 - The Siege of Cuzco: An Analysis of Inca and Spanish Warfare. Colonial Latin American Historical Review, 7 (4): 387-418.

JIJÓN Y CAAMAÑO, J., 1919 - La religión del Imperio de los Incas, 452 p.; Quito: Tipografía y encuadernación Salesianos.

KAULICKE, P., 2004 - Identidad, etnicidad e imperios: algunas reflexiones finales. Boletin de Arqueología, VIII: 325-58; Lima.

MACCORMACK, S. G., 1991-Religion in the Andes: Vision and Imagination in Early Colonial Peru, 488 p.; Princeton, NJ: Princeton University Press.

MACCORMACK, S. G., 1993 - Demons, Imagination, and the Incas. In: New World Encounters (Stephen Greenblatt, ed.): 101-66; Berkeley: University of California Press.

MARTINEZ CERECEDA, J. L., 1995 - Autoridades en los Andes: Los atributos del Señor, 256 p.; Lima: Pontificia Universidad Católica del Perú.

MILLONES, L., 1998 - Logros y azares de la cristianización colonial: El obispado de Huamanga. In: Historia, religion y ritual de los pueblos ayacuchanos (Luis Millones, Hiroyasu Tomeoda \& Tasuhiko Fujii, eds.): 29-49; Osaka, Japan: National Museum of Ethnology.

MORALES, A. de, 1977 - Repartimiento de tierras por el Inca Huayna Capac, 18 p.; Cochabamba, Bolivia: Universidad Boliviana Mayor de San Simón.

MURRA, J. V., 1980 - The Economic Organization of the Inka State, 208 p.; Greenwich, Connecticut: JAI Press.

NOWACK, K., 2004 - Ruling by Proxy. Witness Testimony from Colonial Spanish Legal Proceedings as a Source on Inca Provincial Rule. Trabajo presentado en el «Archives and Empires Conference»; Indiana: University of Notre Dame.

PARSSINEN, M., 1992 - Tawantinsuyu: The Inca State and its Political Organization, 462 p.; Helsinki: Finnish Historical Society.

PATTERSON, T. C., 1991 - The Inca Empire, 211 p.; New York: Berg.

PEASE, F., 1990 - Los Incas en la Colonia. In: El mundo Andino en la época del descubrimiento; Lima: CONCYTEC. Comisión Nacional Peruana del V Centenario del Descubrimiento Encuentro de Dos Mundos.

PEASE, F., 1991 - Los últimos incas del Cuzco, 182 p.; Madrid: Alianza Editorial.

POLO DE ONDEGARDO, LICENCIADO J., 1917 - Relación del linaje de los Incas y cómo extendieron ellos sus conquistas. In: Informaciones acerca de la religión y gobierno de los Incas. Colección de libros y documentos referentes a la Historia del Perú: IV, 45-94; Lima: Imprenta y Librería Sanmarti y Ca. 
QUIPUCAMAYO[C]S, 1920 [1541-1544] - Declaración de los Quipucamayo[c]s a Vaca de Castro. In: Informaciones sobre el antiguo Perú, Secunda ser. 3 (Horacio H. Urteaga, ed.): 3-57; Lima: Imprenta y Librería Sanmartí y Ca.

RAMíREZ, S. E., 1996 - The World Upside Down: Cross-cultural Contact and Conflict in Sixteenth Century Peru, 234 p.; Stanford: Stanford University Press.

RAMíREZ, S. E., 2005 - To Feed and Be Fed: The Cosmological Bases of Authority and Identity in Sixteenth Century Peru, 358 p.; Stanford: Stanford University Press.

RAMÍREZ, S. E., 2006a - From People to Place and Back Again: 'Back Translation' as Decentering, An Andean Case Study. Ethnohistory, 53 (2): 355-82.

RAMÍREZ, S. E., 2006b - Historia y memoria: La construcción de las tradiciones dinásticas andinas. Revista de Indias, LVXI (236): 13-56.

REGALADO DE HURTADO, L., 1993 - Sucesión Incaica, 124 p.; Lima: Pontificia Universidad Católica del Perú.

ROSTWOROWSKI, M., 1977 - Etnia y sociedad: Costa peruana prehispánica, 293 p.; Lima: Instituto de Estudios Peruanos.

ROSTWOROWSKI, M., 1988 - Historia del Tahuantinsuyu, 332 p.; Lima: Instituto de Estudios Peruanos.

ROSWOROWSKI, M., 1989 - Costa Peruana Prehispánica, 318 p.; Lima: Instituto de Estudios Peruanos

ROWE, J. R., 1946 - Inca Culture at the Time of the Spanish Conquest. In: Handbook of South American Indians (Julian H. Steward, ed.): Vol. II; Washington: United States Government Printing Office.

SALOMON, F. \& URIOSTE, J. L., 1991 - The Huarochiri Manuscript, 273 p.; Austin: University of Texas Press.

SANCHO DE LA HOZ, P., 1938 [1534] - Relación para S. M. de lo sucedido en la conquista y pacificación de estas provincias de la Nueva Castilla. In: Los cronistas de la conquista: 117-93; París: Deselée de Brauwer. Biblioteca de cultura peruana, $1^{\text {st }}$ ser., 2.

SANTILLAN, LICENCIADO H. (F.)., 1927 - Relación. In: Colección de libros y documentos referentes a la historia del Perú (Horacio H. Urteaga, ed.) 9: 1-124; Lima: Imprenta y Librería Sanmartí y Ca.

SARMIENTO DE GAMBOA, P. De, 1988 - Historia de los Incas, 191 p.; Madrid: Miraguano Ediciones.

SARMIENTO DE GAMBOA, P. de, 1999 [1907/1972] - History of the Incas, 395 p.; New York: Dover Books.

SILLAR, B. \& DEAN, E., 2002 - Identidad étnica bajo el dominio inca: una evaluación arqueológica y etnohistórica de las repercusiones del Estado Inka en el grupo étnico canas. Boletín de Arqueología, VI: 205-64; Lima.

SZEMINSKI, J., 2001 - Como el pensamiento de los investigadores modernos les impide entender las imágenes indígenas del pasado. In: Actas del 50 Congreso Internacional de Americanistas (Andrezej Dembicz \& Dorota Olejniczank, eds.): 163-77; Warsaw: Center for Latin American Studies, Warsaw University.

VALCARCEL, D., 1961 - Historia de la educación Incaica, 143 p.; Lima: Universidad Nacional Mayor de San Marcos.

VARÓN GABAI, R., 1993 - Estrategias políticas y relaciones conyugales: El comportamiento de Incas y Españoles en Huaylas en la primera mitad del siglo XVI. Bulletin de I'Institut Français d'Études Andines, 22 (3): 721-37. 
VILLANUEVA URTEAGA, H., 1986 - Los curacas de Cajamarca. In: Historia de Cajamarca (Fernando Silva Santisteban, Waldemar Espinoza Soriano \& Rogger Ravines, eds.): Vol. II: 337-42; Cajamarca: Instituto Nacional de Cultura.

WACHTEL, N., 1977 - The Vision of the Vanquished: The Spanish Conquest of Peru through Indian Eyes, 1530-1570, 328 p.; New York: Barnes and Noble.

ZIOLKOWSKI, J., 1991 - El culto estatal del imperio Inca, 173 p.; Warsaw, Poland: University of Varsovia, Centro de Estudios Latinoamericanos. 